\title{
Functional outcome of retrograde nailing versus locked plating of extra-articular distal femoral fractures in adults: A randomized controlled trial
}

\section{Yadar $\mathrm{CB}^{1}{ }^{1 D \otimes}$, Rajak $\mathrm{A}^{2}$, Shrestha $\mathrm{BP}^{3}$, Rijal R $\mathrm{R}^{4}$, Maharjan $\mathrm{R}^{5}$, Kalawar $\mathrm{RPS}^{6}$, Limbu $\mathrm{A}^{7}$}

${ }^{1}$ Chandra Bhusan Yadav, Consultant; ${ }^{2}$ Asish Rajak, Lecturer; ${ }^{3}$ Bikram Prasad Shrestha, Professor; ${ }^{4}$ Raju Rijal, Professor; ${ }^{5}$ Rajiv Maharjan, Additional Professor; ${ }^{6}$ Rosan PS Kalawar, Associate Professor; ${ }^{7}$ Amit Limbu, Assistant Professor, Department of Orthopaedics, B.P. Koirala Institute of Health Sciences, Dharan, Sunsari, Nepal.

\begin{abstract}
Background: Distal femoral fracture constitutes the supracondylar and intercondylar fractures of femur. These are treated by locking plates as well as with nails. Despite the widespread use of both techniques, there are only few comparative studies. The two clinical techniques used to stabilize distal femur fractures are compared in this study.

Objectives: The aim of this study was to compare plating and nailing in terms of functional outcome using the Hospital for Special Surgery (HSS) Knee Score of operative fixation of extra-articular femur fracture.

Methodology: A randomized controlled trial was conducted with a total of 30 patients presenting to BP Koirala Institute of Health Sciences in a period of twelve months. All skeletally mature ( $>16$ years) adult patients with isolated traumatic closed extra-articular fracture of distal femur without distal neurovascular deficit and giving written and informed consent were included. Patients with re-fractures, poly-trauma, fracture dislocations, pathological fracture and compartment syndrome were excluded. They were operated and followed up at 2, 6, 12 and 24 weeks.

Results: The demographic profiles of the two groups were comparable. There was no significant difference in functional outcome (Hospital for Special Surgery score), union or complications between them.

Conclusion: This study showed that there was no significant difference in terms of functional outcome (Hospital for Special Surgery score), union, fracture alignment, range of motion (knee, hip joint), infection, other outcome measures between plating and nailing in the treatment of distal femoral fracture in adults. Hence, further study is required to come to firm conclusions.
\end{abstract}

Key words: Distal femur; Fracture; Nailing; Plating.

\section{Access this article online}

Website: www.jkmc.com.np

DOI: https://doi.org/10.3126/jkmc.v9i3.36404

HOW TO CITE

Yadav CB, Rajak A, Shrestha BP, Rijal R, Maharjan R, Kalawar RPS, Limbu $A$. Functional outcome of retrograde nailing versus locked plating of extra-articular distal femoral fractures in adults: A randomized controlled trial. J Kathmandu Med Coll. 2020;9(3):1229.

Address for correspondence

\section{Dr. Chandra Bhusan Yadav}

Department of Orthopaedics

B.P. Koirala Institute of Health Sciences

Dharan, Sunsari, Nepal.

E-mail: chandru1986.cy@gmail.com

Copyright $\odot 2020$ Journal of Kathmandu Medical College (JKMC) ISSN: 2019-1785 (Print), 2091-1793 (Online)

(i) (5) This work is licensed under a Creative Commons Attribution-Non Commercial 4.0 International License.

\section{INTRODUCTION}

istal femoral fractures constitute the supracondylar and intercondylar fractures of femur. Incidence is highest in women older than 75 years usually associated with low energy injuries and young men (15- 24 years) mostly associated with high energy injuries. Various fixation options are available but no single method of management has overcome all of the problems associated with these injuries. Fixed angle locking plates have become the most commonly used device replacing others ${ }^{1}$. The main advantage of an anatomically precontoured locked plate is soft-tissue protection using a limited approach ${ }^{2,3}$. One concern with locking plate constructs is that the high stiffness achieved may limit the amount of callus, resulting in delayed healing or non-union ${ }^{4}$. Retrograde intramedullary femoral nailing is a 'biological' method, which is preferred by some surgeons for its good control of the distal fragment $5,6,6,8$. Despite the widespread use of both techniques, only few 
clinical studies have directly compared locked plates to nails ${ }^{9}$. The purpose of this study is to compare between the two mostly in terms of HSS (Hospital for Special Surgery) Knee score.

\section{METHODOLOGY}

The study was a prospective randomized controlled trial conducted at the Department of Orthopaedics, B.P. Koirala Institute of Health Sciences, a tertiary care hospital in Eastern Nepal, over a period of twelve months between Sep 2016 to August 2017. Ethical clearance was obtained from the Institutional Review Committee (IRC). All skeletally mature ( $>16$ years) adult patients with isolated traumatic open (Gustilo Grade I and II fractures), closed extra-articular fracture of distal femur without distal neurovascular deficit presenting to Emergency and the outpatient department; giving written and informed consent were included in the study. Patients with re-fractures, poly-trauma, fracture dislocations, pathological fracture and compartment syndrome were excluded.

The null hypothesis was that there is no significant difference in functional outcome between the two implants namely IMILN and Plating for treatment of distal femur in adults. The primary objective of the study was to compare the functional outcome and efficacy of retrograde nailing and plating for treatment of extra articular distal femur fracture. The secondary objectives were to determine the time required for fracture union and complications related to fracture and implant.

The sample size was calculated considering $95 \% \mathrm{Cl}$ and $80 \%$ power of the study and with reference to the study by Gao K et al ${ }^{5}$. The calculated sample size was 15 for each group (total 30). Randomization was done by random number allocation using Microsoft Excel random number generation technique.

The patients were administered analgesics and traction was applied to the affected limb. A prior informed and written consent was taken from each patient after explaining about the procedures, complications and possible outcomes. A thorough general physical and systemic examination was carried out to look for underlying exclusion criteria. All cases were admitted, history was obtained and clinical examination was done with recording of any distal neurovascular deficit. Diagnosis was confirmed by $\mathrm{x}$-ray of the thigh with knee on lateral and antero-posterior views. Classification of the fracture was done according to AO classification. Skeletal traction was applied. Relevant pre-operative investigations were sent. After the patient was found to be fit for anaesthesia the patient was planned for surgery on elective basis.

The same type and strength of pre-operative antibiotics (cefuroxime $1.5 \mathrm{mg}$ IV stat and amikacin 500 mg IV stat) was administered in all cases within one hour of incision and continued for the same duration (48 hours) post operatively for all patients with closed fractures. Patients with open fractures were also randomized and given additional metronidazole $500 \mathrm{mg}$ IV for 5 days. After adequate anaesthesia, the patient was positioned in supine position on the fracture table for group $A$ (plating) and in radiolucent table for group $B$ (retrograde nailing).

The further surgical exposure step was different as per the study groups.

In the plating group, whenever possible Minimally Invasive percutaneous plate osteosynthesis (MIPPO) was done; in cases which needed to be openly reduced or later converted to open; a lateral skin incision was made along the postero-lateral border of femur extending from lateral femoral epicondyle, exact length of incision depending on length of plate being applied. A plane was made between vastus lateralis muscle and lateral intermuscular septum, which covers the hamstring muscles. A distal femoral locking plate of adequate length was applied on the lateral surface of femur.

In the nailing group, a midline longitudinal skin incision was made over the knee. A medial para-patellar arthrotomy was done and a nail of adequate length and diameter was inserted through the intercondylar notch of femur just anterior to the attachment of posterior cruciate ligament $(\mathrm{PCL})$. Locking bolts were applied proximally and distally under image guidance.

All the intraoperative parameters like blood loss, duration of surgery were noted as per pro forma and recorded. Antibiotics were administered parenterally for similar duration in both groups. On the 2nd post-operative day, the surgical wound was inspected and range of motion (ROM), quadriceps and hamstring strengthening exercises were taught by trained physiotherapists. Non weight bearing axillary crutch walking was taught. No post-op splinting of the limb was done. Check x-ray was done to see adequate placement of implants. Postoperative complications e.g. excessive soakage, postoperative distal neurovascular deficit if any and pain (VAS - Visual Analogue Scale score) was noted and recorded. The wound was inspected on second post-operative day and the patient discharged if satisfactory. 
The patients were followed up at 2, 6, 12 and 24 weeks. It was an 'Intention to treat analysis', therefore even though the sample size is small but yet sufficient, we considered everyone who was randomized being part of the study irrespective of the outcome and the follow- up duration completed. The surgical wound was inspected at two weeks and sutures removed. Patients were then followed up in out-patient department at six weeks with check $x$-rays. Patients were taught range of motion exercise, exercise of knee joint and isometric quadriceps exercises. Range of motion, clinical and radiological signs of fracture union, deformity, and time taken for functional recovery was assessed as per the pro forma. Both groups were advised for non-weight bearing crutch walking till six weeks. After that, the plating group was continued with non-weight bearing crutch walking while the nailing group was allowed partial weight bearing after six weeks. At the end of three and six months, results were graded using the HSS score. Statistical Package for the Social Sciences (SPSS) software was used for statistical analysis and $\mathrm{p}<0.05$ was considered statistically significant. Collected data were entered in Microsoft Excel 2013 and converted into SPSS version 11.5 for statistical analysis. For descriptive analysisproportion, percentage, mean and standard deviation were calculated. Graphical and tabular presentations were made. For inferential statistics- Chi-square test for categorical data, t-test or Mann Whitney $U$ test for continuous data was applied to find out the significant differences between the two groups (retrograde IMLIN group and plating group) with study variables at $95 \%$ confidence interval where $p$-value $=0.05$. Fisher's Exact test was used for test of independence.

\section{RESULTS}

\section{CONSORT DIAGRAM}

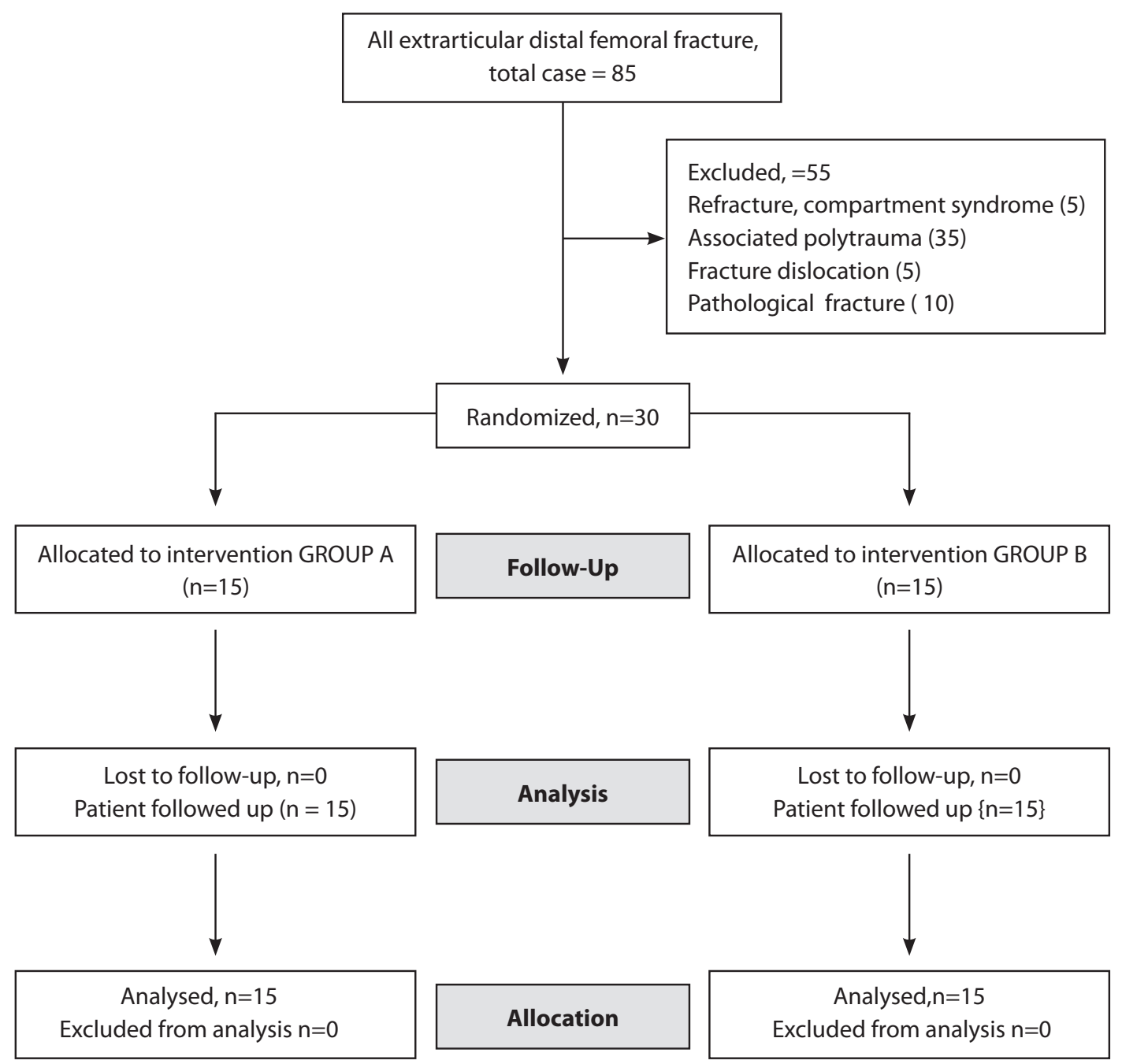


A total of 30 cases were operated over the study period of which 14 were males and 16 were females. Most of them were in the $36-45$ years age group $(n=30)$. The mode of injury was similar between the groups. All of these variables were not statistically significant suggesting that randomization was successful (Table 1).

The timing of presentation after surgery and injury to surgery time was not statistically significant (Table 2). The amount of blood loss (mean haemoglobin difference) was not significant between the two groups (Table 10). The early post-operative complications were similar in both groups. One patient in the plating group developed late infection (Table 3,4). The patient was managed with IV and local antibiotics for two weeks after which the infection subsided.
Signs of healing were present in all except one case of plating at 12 weeks (Table 5), which showed signs of healing at 24 weeks. All cases were ambulatory with either partial or full weight bearing in 12 weeks (Table 6).

Pain measured with VAS score showed gradual improvement in pain over time in both the groups. The VAS score was significant at six weeks in the nailing group (Table 7). The reason may be because the knee joint is opened with mobilization of capsule or cartilage during the surgical approach or pain can be due to nail impingement on patella.

The functional score (HSS score) was comparable between the groups at final follow up (Table 9).

Table 1: Demographic profile of the patients

\begin{tabular}{|c|c|c|c|c|}
\hline \multirow{2}{*}{ Characteristics } & & \multicolumn{2}{|c|}{ Group } & \multirow{2}{*}{ p-value } \\
\hline & & Plating & Nailing & \\
\hline \multicolumn{2}{|c|}{ Mean Age \pm SD (years) } & $36.6 \pm 17.5$ & $45.5 \pm 19.1$ & 0.197 \\
\hline \multirow{2}{*}{ Sex } & Male & 8 & 6 & \multirow{2}{*}{0.273} \\
\hline & Female & 7 & 9 & \\
\hline \multirow{3}{*}{ Mode } & Road Traffic Accident & 8 & 7 & \multirow{3}{*}{0.693} \\
\hline & $\begin{array}{l}\text { Fall from Ht/ Slip on } \\
\text { ground }\end{array}$ & 5 & 7 & \\
\hline & Physical assault & 2 & 1 & \\
\hline \multirow{2}{*}{ Nature of fracture } & Closed & 13 & 13 & \multirow{2}{*}{1} \\
\hline & Open & 2 & 2 & \\
\hline
\end{tabular}

Table 2: Distribution of different variables among two groups

\begin{tabular}{lcccc}
\hline Injury and hospital arrival time & Plating & Nailing & p-value & Remarks \\
\hline$<12$ hours & 10 & 9 & 0.943 \\
\hline 12 hours - 1 day & 3 & 3 & Not-significant \\
$>1$ day - 1 week & 1 & 2 & p-value \\
\hline$>1$ week & 1 & Nailing & Remarks \\
\hline Injury- Surgery Interval & Plating & 0 & 0.131 & Not significant \\
\hline Upto 1 day & 1 & 10 & 5 & \\
\hline 1 day -1 week & 13 & 1 & \\
\hline$>1$ week & 1 & & \\
\hline
\end{tabular}

Table 3: Early post-operative complications

\begin{tabular}{lcccc}
\hline & Plating & Nailing & p-value & Remarks \\
Redness/surgical site discharge & 4 & 1 & & Not significant \\
Swelling & 3 & 3 & 0.321 & Not significant \\
\hline None & 8 & 11 & & 0.443 \\
\hline Post-op pain VAS Score (mean \pm SD) & $8.26 \pm 0.59$ & $8.067 \pm 0.79$ & & \\
\hline
\end{tabular}


Table 4: Delayed post-operative complications

\begin{tabular}{lcccc}
\hline Infection & Plating & Nailing & p-value & Remarks \\
\hline Present & 1 & 0 & 0.309 & Not-significant \\
\hline Absent & 14 & 15 & & \\
\hline
\end{tabular}

Table 5: Analysis of clinico-radiological union at 12 weeks

Radiological signs of union (callus formation) between the two groups (Fisher`s Test) at 12 weeks

$\begin{array}{lcccc}\text { Callus } & \text { Plating } & \text { Nailing } & \text { p-value } & \text { Remarks } \\ \text { Present } & 14 & 15 & 0.309 & \text { Not significant } \\ \text { Absent } & 1 & 0 & & \end{array}$

Clinical signs of union between the two groups (Fisher`s Test) at 12 weeks.

\begin{tabular}{lcccc} 
Clinical signs of union & Plating & Nailing & p-value & Remarks \\
\hline Present & 14 & 15 & 0.309 & Not-significant \\
\hline Absent & 1 & 0 & & \\
\hline
\end{tabular}

Table 6: Ambulatory status at 12 weeks

\begin{tabular}{lcccc}
\hline Ambulatory status & Plating & Nailing & p-value & Remarks \\
\hline Non weight bearing & 0 & 0 & & Not significant \\
Partial weight bearing & 6 & 5 & 0.705 & \\
\hline Full weight bearing & 9 & 10 & & \\
\hline
\end{tabular}

Table 7: VAS score for pain at different follow-up

\begin{tabular}{|lcccc}
\hline VAS score (mean \pm SD) & Plating & Nailing & p-value & Remarks \\
\hline Post- op & $8.26 \pm 0.59$ & $8.067 \pm 0.79$ & 0.443 & significant \\
\hline 2 weeks & $2.80 \pm 1.01$ & $3.26 \pm 0.79$ & 0.172 & At 6 weeks \\
\hline 6 weeks & $2.067 \pm 0.88$ & $2.80 \pm 0.67$ & 0.016 & 0.876 \\
\hline 12 weeks & $1.20 \pm 1.08$ & $1.26 \pm 1.22$ & \\
\hline
\end{tabular}

Table 8: Range of motion (Hip, knee)

(a) ROM knee between the two groups at different stages of follow-up

\begin{tabular}{lcccc}
\hline ROM knee (mean + SD) & Plating (degree) & Nailing (degree) & p-value & Remarks \\
\hline 2 weeks & $84+8.28$ & $87.33+5.93$ & 0.216 \\
\hline 6 weeks & $100.66+10.99$ & $102.0+8.61$ & 0.714 & Not significant \\
\hline 12 weeks & $106.6+9.75$ & $107.33+8.83$ & 0.846 \\
\hline
\end{tabular}

(b) ROM hip between the two groups at different stages of follow-up

\begin{tabular}{lcccc}
\hline ROM hip (mean + SD) & Plating & Nailing & p-value & Remarks \\
\hline 2 weeks & $53.0+/-17.29$ & $65.0+/-9.81$ & 0.027 & Significant at 2 and 6 \\
\hline 6 weeks & $75.33+/-20.30$ & $86.66+/-8.16$ & 0.055 & weeks and not at 12 \\
\hline 12 weeks & $94.00+/-21.89$ & $104.0+/-9.85$ & 0.118 & weeks \\
\hline
\end{tabular}

Table 9: HSS Score criteria for final outcome between $\mathbf{2}$ groups

\begin{tabular}{cccc}
\hline & No. of patients & HSS (mean + SD) & p-value \\
\hline Plating & 15 & $66.1+/-13.1$ & 0.157 \\
\hline Nailing & 15 & $71.7+/-7.1$ & \\
\hline
\end{tabular}


Table 10: The pre-op Hb (Independent Samples T-test) between the 2 groups

\begin{tabular}{ccccc}
\hline Variable(mean+/-SD) & Plating & Nailing & p-value & Remark \\
\hline Hb pre-op & $11.453+/-1.780$ & $11.51+/-1.989$ & 0.812 & Not significant \\
\hline Hb post-op & $10.3133+/-1.78$ & $10.71+/-1.996$ & 0.906 & \\
\hline Hb difference & $1.1467+/-0.360$ & $0.74+/-0.279$ & 0.543 & \\
\hline
\end{tabular}

Table 11: Implant failure between 2 groups at 12 weeks

\begin{tabular}{cccc}
\hline Implant failure & Plating & Nailing & p-value \\
\hline Present & 0 & 0 & N/A \\
Absent & 15 & 15 & N/A \\
\hline
\end{tabular}

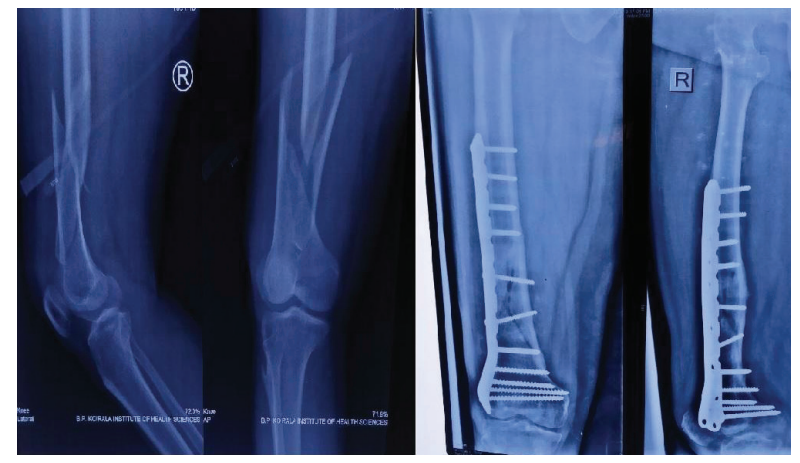

Figure 1: Post-operative $\mathrm{x}$-ray at 12 weeks of plating group

\section{DISCUSSION}

The treatment of extra-articular distal femoral fracture is done mainly through plating or nailing. In our study, the amount of blood loss (mean haemoglobin difference) was not significant between the two groups, which was different to the study by Gao K et al where mean blood loss was more in nailing group as compared to the plating group. The MIPPO technique in the study more commonly used for plating may be the possible cause for less blood loss as compared to retrograde nailing where knee joint is opened ${ }^{5}$.

In our study, there was no significant difference in the occurrence of early post-operative complications (redness, discharge from surgical site, limb swelling) between the two groups. Seven patients $(23 \%)$ in the plating group and four patients (13.3\%) in nailing had early post-operative complication. In a study by Gupta et al, no complications were noticed in patients of plating group, but limitation of this study was that the patients were not randomized to each group ${ }^{7}$.

Pain was evaluated using VAS score. It gradually decreased over a passage of time after operation and it

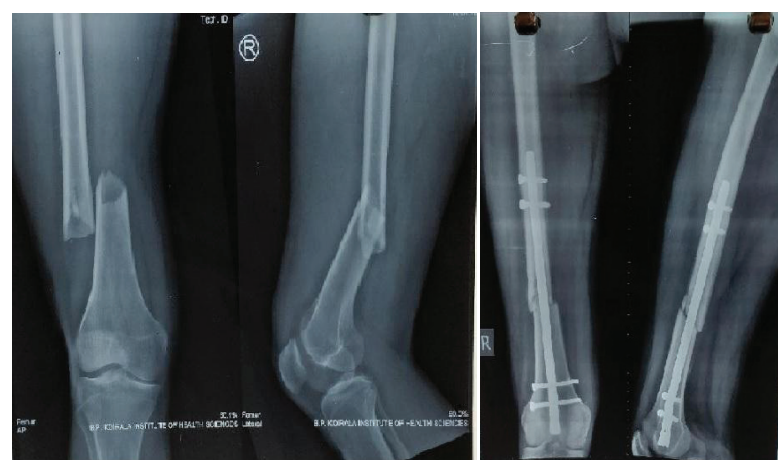

Figure 2: Post-operative $x$-ray at 12 weeks of nailing group

was found that the difference in pain between the two groups was significant at six weeks, the pain was found to be more in the nailing group. During retrograde nailing the knee joint is opened, the mobilization of capsule or cartilage during the surgical approach may be the reason for pain during weight bearing or pain can be due to nail impingement on patella. The result was similar to a study by Hartin et al where they had concluded that more pain in nailing group was the reason for a greater trend of revision surgery for implant removal in the nailing group $^{13}$.

The average ROM of knee joint was more for nailing group with respect to plating group at different followup; although it was not significant statistically, our result was similar to the study of Gao K et al.

In a one-year follow-up study by Markmiller et al average hip ROM was found more for plating group ${ }^{16}$.

We found the difference between ROM hip significant at 2 and 6 weeks, the less ROM hip in plating group may be because, during surgical approach for plating we divide the tensor fascia lata (TFL), which assist in flexion, medial 
rotation and abduction of hip joint, thus hip joint motion remains compromised till the muscle heals ${ }^{22}$.

In our study, there was no significant difference between the groups in fracture union at 12 weeks follow-up ${ }^{10}$. HSS score criteria for evaluation of final outcome was similar for both groups with mean score of 66.1 for plating group and 71.7 for nailing group. No significant difference $(p$-value $=0.157$ ) was noted between the two groups as regard to final outcome. This result was similar to the study by Gao K et al ${ }^{5}$.

Our study had limitations due to a smaller number of sample size and less duration of follow-up due to which removal of implants after union could not be evaluated and late complications such as arthritis of the knee joint could not be studied. Also, the note of the fracture pattern according to $\mathrm{AO}$ was not done and power of

\section{REFERENCES}

1. Claes LE, Heigele CA, Neidlinger-Wilke C, Kaspar D, Seidl W, Margevicius KJ, et al. Effects of Mechanical Factors on the Fracture Healing Process. A Publ Assoc Bone Jt. 1998;355. [DOI]

2. Duda GN, Sollmann M, Sporrer S, Hoffmann JE, Kassi JP, Khodadadyan C, et al. Interfragmentary Motion in Tibial Osteotomies Stabilized With Ring Fixators. A Publ Assoc Bone Jt Surg. 2002;396:163-72. [DOI]

3. Egol KA, Kubiak EN, Fulkerson E, Kummer FJ, Koval $\mathrm{KJ}$. Biomechanics of locked plates and screws. Journal of Orthopaedic Trauma. 2004 Sep;18(8):48893. [DOI]

4. Ehlinger M, Ducrot G, Adam P, Bonnomet F. Distal femur fractures. Surgical techniques and a review of the literature. Orthop Traumatol Surg Res. 2013 May;99(3):353-60. [DOI]

5. Kanda G, Gao K, Gao W, Huang J, Li H, Li F, et al. Retrograde Nailing versus Locked Plating of ExtraArticular Distal Femoral Fractures: Comparison of 36 Cases. Med Princ Pract. 2013;22(2):161-6. [DOI]

6. Gupta S, Govindappa C, Yalamanchili R. Outcome of retrograde intramedullary nailing and locking compression plating of distal femoral fractures in adults. OA Orthopaedics. 2013;1(3). [DOI]

7. Heiney JP, Barnett MD, Vrabec GA, Schoenfeld AJ, Baji A, Njus GO. Distal femoral fixation: a biomechanical comparison of trigen retrograde intramedullary (i.m.) nail, dynamic condylar screw (DCS), and locking compression plate (LCP) condylar plate. J Trauma. 2009 Feb;66(2):443-9. [DOI]

8. Henderson CE, Lujan T, Bottlang M, Fitzpatrick DC, muscles around the knee and hip was not assessed between the groups which would have added to the value of the study.

\section{CONCLUSION}

Both treatment methods were identical in terms of functional outcome (HSS score), union, ROM (knee, hip joint), infection, implant failure and other outcome measures between plating and nailing till follow-up of six months in the treatment of distal femoral fracture in adults. Hence, both can be chosen as a method of treatment according to clinical judgement. However, further research with larger sample size and longer follow-up will be needed to validate the findings of this study.

\section{Conflict of interest: None Source(s) of support: None}

Madey SM, Marsh JL. Stabilization of distal femur fractures with intramedullary nails and locking plates: differences in callus formation. lowa Orthop J. 2010;30:61-8.

9. Hierholzer C, von Rüden C, Pötzel T, Woltmann A, Bühren $V$. Outcome analysis of retrograde nailing and less invasive stabilization system in distal femoral fractures: A retrospective analysis. Indian J Orthop. 2011 May;45(3):243-50. [DOI]

10. Kolb W, Guhlmann H, Windisch C, Marx F, Kolb K, Koller $\mathrm{H}$. Fixation of distal femoral fractures with the Less Invasive Stabilization System: a minimally invasive treatment with locked fixed-angle screws. J Trauma. 2008 Dec;65(6):1425-34. [DOI]

11. Thomson A, Driver R, Kregor P, Obremskey W. Longterm Functional Outcomes After Intra-articular Distal Femur Fractures: ORIF Versus Retrograde Intramedullary Nailing. Orthopedics. 2008; 31(8):748-50. [DOI]

12. Neubauer $T$, Krawany $M$, Leitner L, Karlbauer A, Wagner M, Plecko M. Retrograde Femoral Nailing in Elderly Patients: Outcome and Functional Results. Orthopedics. 2012;35:e855-e61. [DOI]

13. Hartin NL, Harris I, Hazratwala K. Retrograde nailing versus fixed-angle blade plating for supracondylar femoral fractures: A randomized controlled trial. ANZ J Surg. 2006 May 1;76(5):290-4. [DOI]

14. Herrera DA, Kregor PJ, Cole PA, Levy BA, Jönsson A, Zlowodzki M. Treatment of acute distal femur fractures above a total knee arthroplasty: Systematic review of 415 cases (1981-2006). Acta Orthop. 2008 Jan 1;79(1):22-7. [DOI] 
15. Goodship AE, Kenwright J. The influence of induced micromovement upon the healing of experimental tibial fractures. J Bone Joint Surg Br. 1985 Aug 1;67$\mathrm{B}(4): 650-5$. [DOI]

16. Markmiller M, Konrad G, Südkamp N. Femur-LISS and Distal Femoral Nail for Fixation of Distal Femoral Fractures: Are There Differences in Outcome and Complications? A Publ Assoc Bone Jt Surg. 2004;426:252-7. [DOI]

17. Kubiak E, Fulkerson E, Strauss E, Egol K. The Evolution of Locked Plates. J Bone Joint Surg Am. 2007 Jan 1;88 Suppl 4:189-200. [DOI]

18. Lujan TJ, Henderson CE, Madey SM, Fitzpatrick DC, Marsh JL, Bottlang M. Locked Plating of Distal Femur Fractures Leads to Inconsistent and Asymmetric
Callus Formation. J Orthop Trauma. 2010;24(3):15662. [DOI]

19. Ostrum RF, Maurer JP. Distal Third Femur Fractures Treated With Retrograde Femoral Nailing and Blocking Screws. J Orthop Trauma. 2009;23(9):6814. [DOI]

20. Perren SM. Evolution of the internal fixation of long bone fractures. J Bone Joint Surg Br. 2002 Nov 1;84$\mathrm{B}(8): 1093-110$. [DOI]

21. Pospula W, Abu Noor T: Periprosthetic Fractures of the Femur after Hip and Knee Replacement. Med Princ Pract. 2009;18:198-203. [DOI]

22. Tucker J, DC, DACRB. Functional evaluation Tensor Fascia lata and iliotibial band. Dynamic chiropractic. 2007 Nov 19;25(24). [Full Text] 